\title{
Trivalent Live-Attenuated Influenza Vaccine
}

National Cancer Institute

\section{Source}

National Cancer Institute. Trivalent Live-Attenuated Influenza Vaccine. NCI Thesaurus. Code C101094.

A weakened live virus vaccine containing three seasonal influenza reassortants with prophylactic activity against influenza subtypes A and B. The trivalent live-attenuated influenza vaccine (LAIV) contains 2 strains of the influenza subtype A, one for H1N1 and one for H3N2, and one strain of subtype B. Upon intranasal administration by sprayer of the trivalent LAIV, the live viruses replicate in the upper respiratory tract and induce an immune response leading to active immunization against influenza subtypes A and B. 